\title{
KETENE FORMATION IN INTERSTELLAR ICES: A LABORATORY STUDY
}

\author{
RegGie L. Hudson AND MARK J. LOEFFler \\ Astrochemistry Laboratory, NASA Goddard Space Flight Center, Greenbelt, MD 20771, USA; Reggie.Hudson@NASA.gov \\ Received 2012 December 4; accepted 2013 June 23; published 2013 July 31
}

\begin{abstract}
The formation of ketene $\left(\mathrm{H}_{2} \mathrm{CCO}\right.$, ethenone) in polar and apolar ices was studied with in situ $0.8 \mathrm{MeV}$ proton irradiation, far-UV photolysis, and infrared spectroscopic analyses at 10-20 K. Using isotopically enriched reagents, unequivocal evidence was obtained for ketene synthesis in $\mathrm{H}_{2} \mathrm{O}$-rich and $\mathrm{CO}_{2}$-rich ices, and several reaction products were identified. Results from scavenging experiments suggested that ketene was formed by free-radical pathways, as opposed to acid-base processes or redox reactions. Finally, we use our results to draw conclusions about the formation and stability of ketene in the interstellar medium.
\end{abstract}

Key words: astrobiology - astrochemistry - ISM: molecules - molecular data - molecular processes

\section{INTRODUCTION}

Ketene $\left(\mathrm{H}_{2} \mathrm{CCO}\right)$, also called ethenone, is a 16-valence electron molecule with a photo- and thermal chemistry that has been extensively studied by laboratory scientists. Ketene readily converts into other compounds, for example combining with $\mathrm{H}_{2} \mathrm{O}$ to make acetic acid, with $\mathrm{NH}_{3}$ to make acetamide, and with $\mathrm{CH}_{3} \mathrm{OH}$ to make methyl acetate. See Figure 1. Reactions of ketene and similar molecules include dimerization, acylation, cycloadditions, and polymerization. Ketene dissociation gives methylene $\left(\mathrm{CH}_{2}\right)$, which undergoes a wide variety of organic reactions, some of which give ketene an astrobiological importance. For example, $\mathrm{CH}_{2}$ in its ${ }^{3} B_{1}$ electronic ground state can insert itself into $\mathrm{C}-\mathrm{H}$ chemical bonds and extend the length of a carbon chain. In its ${ }^{1} A_{1}$ singlet excited state, $\mathrm{CH}_{2}$ can add across double bonds to form cyclic compounds, and even insert into rings to enlarge them. An introduction to the extensive chemical literature on ketene is provided by reviews of Tidwell (1990, 2005) and Allen \& Tidwell (2012), with older publications still being valuable (e.g., Wilsmore \& Stewart 1907; Staudinger 1912; Hagemeyer 1949; Quadbeck 1956). Recent papers on synthetic applications of ketene-type molecules include Orr \& Calter (2003) and Paull et al. (2009).

For astronomers, ketene has long been recognized as an interstellar molecule. It first was detected in the gas phase through the microwave measurements of Turner (1977), which were confirmed and extended by other investigators (Johansson et al. 1984; Irvine et al. 1989; Turner et al. 1999). Continued interest in this molecule is shown by recent gas-phase detections of ketene in a prestellar core (Bacmann et al. 2012, abundance $\sim 10^{13} \mathrm{~cm}^{-2}$ ) and in an extragalactic source (Muller et al. 2011, abundance $\sim 10^{-10}$ relative to $\mathrm{H}_{2}$ ). The formation reactions for interstellar ketene are at present unknown and have even been said to be "subject to controversy" (Muller et al. 2011). Gasphase production models (Herbst \& Leung 1986) have been invoked, as have models in which ketene is formed on grains and later removed to the gas phase (Charnley et al. 1992). Ruiterkamp et al. (2007) discussed such scenarios and pointed out difficulties in each, as did Bacmann et al. (2012).

Aside from being an interstellar species, ketene also has connections to many known and suspected astronomical molecules. Ketene is isoelectronic with several well-known 16-valence electron interstellar species, such as $\mathrm{CO}_{2}, \mathrm{~N}_{2} \mathrm{O}, \mathrm{HNCO}$, $\mathrm{H}_{2} \mathrm{CCNH}$, and $\mathrm{OCN}^{-}$, and is a reduced form of the $\mathrm{C}_{2} \mathrm{O}$ (ketenylidene) radical, which is known to be interstellar. Ketene can be considered a parent compound of the cumulenones, molecules with the structure $\mathrm{H}_{2} \mathrm{C}=\mathrm{C}=(\mathrm{C})_{n}=\mathrm{O}(n>0)$, and which have been sought in the interstellar medium (Brown et al. 1991). Carbon suboxide $\left(\mathrm{C}_{3} \mathrm{O}_{2}\right)$ was the first member of the bisketenes, $\mathrm{O}=\mathrm{C}=(\mathrm{C})_{n}=\mathrm{C}=\mathrm{O}$, to be synthesized. It has been sought in Comet Halley (Crovisier et al. 1991) and is of interest to laboratory astrochemists (Gerakines et al. 2001).

Despite all of these astrochemical connections, little laboratory work is available to help understand ketene's formation in the interstellar medium. Moreover, in contrast to the large amount of work done on gas-phase ketene, little has been published on the formation and reaction chemistry of solid-phase ketene under conditions of interest to astronomers and astrochemists. Schriver et al. (2004) studied the UV photolysis of ethylene oxide $\left(c-\mathrm{OCH}_{2} \mathrm{CH}_{2}\right)$ in $\mathrm{H}_{2} \mathrm{O}$-ice and identified acetaldehyde $\left(\mathrm{HC}(=\mathrm{O}) \mathrm{CH}_{3}\right), \mathrm{CH}_{4}$, and $\mathrm{CO}$ as photo-products. Although ketene was seen isolated in UV-photolyzed argon + ethylene oxide (1000:1) solids, no ketene was observed in the more astrochemically relevant $\mathrm{H}_{2} \mathrm{O}$-rich ices. Later reports on the electron irradiation of 6:1 $\mathrm{CO}+\mathrm{CH}_{4}$ (Bennett et al. 2005a) and 2:1 $\mathrm{CO}_{2}+\mathrm{C}_{2} \mathrm{H}_{4}$ (Bennett et al. 2005b) ices also failed to identify ketene.

Beyond the astrochemical literature, numerous investigations have resulted in the identification of ketene as a solid-phase reaction product, but to our knowledge all such experiments have involved chemical precursors, icy matrices, or ice components that are unlikely to occur or are of low abundance in an astronomical setting. As examples, acetone (Zhang et al. 1997), acetic acid (Macoas et al. 2004), thioacetic acid (Romano et al. 2002), acetyl chloride (Rowland \& Hess 1997), acetyl cyanide (Guennoun et al. 2005), and diazoacetaldehyde (Krantz 1973) all undergo solid-phase, low-temperature decomposition to give ketene, but none of these precursor molecules are expected to have a high abundance in astronomical ices.

Because of this paucity of laboratory data on reaction paths leading to ketene in astronomical ices, here we bring together some earlier experimental observations related to this molecule and place them, and some of our new experimental results, into a context that emphasizes the ease of ketene formation in interstellar ice analogs. We examine two types of ices, one made of apolar components and the other dominated by $\mathrm{H}_{2} \mathrm{O}$, a strongly polar molecule, with an emphasis on radiation-chemical methods and support from photochemistry experiments. The present work differs from previous studies in that for ketene precursors we only use molecules that have been detected in the interstellar 


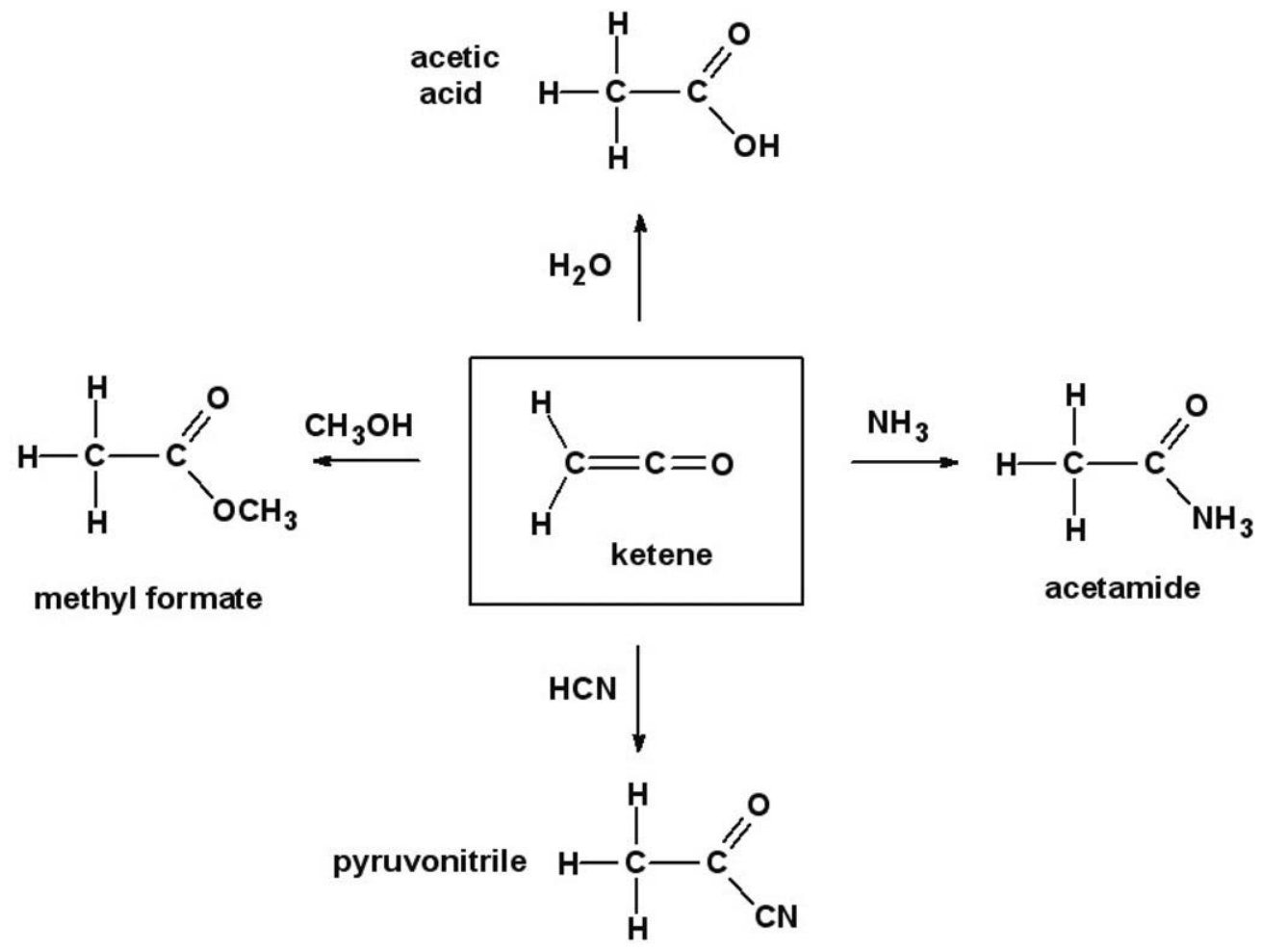

Figure 1. Four laboratory addition reactions of ketene. See Staudinger (1912), Wang \& Schueler (1949), Quadbeck (1956), and references therein for details.

medium or that are suspected to interstellar. In this way, we continue our laboratory investigations of low-temperature reactions that lead to astronomical molecules either seen or suspected in interstellar and planetary environments.

\section{ICES AND RADIATION CHEMISTRY}

In our experiments, ices were exposed to a beam of $0.8 \mathrm{MeV}$ protons $\left(p^{+}\right)$to initiate radiation-chemical changes at $10-20 \mathrm{~K}$. At this energy, a single $p^{+}$passing through an ice produces a trail of thousands of ionizations and excitations as its energy is degraded. Many such ionizations will produce secondary electrons which, in turn, create separate tracks of yet more ionizations and excitations leading to further chemical changes. In this way, which we emphasize, the direct chemical action of the initial $\mathrm{MeV}$ radiation is completely overshadowed by that from secondary electrons of energies less than $\sim 20 \mathrm{eV}$ (Pimblott \& LaVerne 2007). Therefore, to a strong first approximation the products of various ionizing radiations (e.g., $e^{-}, p^{+}, \mathrm{He}^{+}$, $\mathrm{X}$-rays, $\gamma$-rays) are identical, and strongly resemble those of UV photochemistry (Spinks \& Woods 1964; Hudson et al. 2001; Hudson \& Moore 2000). In the present work, this similarity in chemical products meant that we were able to use photochemical experiments, which were relatively fast and inexpensive, as a way to anticipate the results of ion irradiations, which were more costly to obtain.

A final point concerns the $\mathrm{GeV}$ particle energies available in the interstellar medium in comparison to our $0.8 \mathrm{MeV}$ protons. Although $\mathrm{GeV}$ ions penetrate more deeply into ices than $\mathrm{MeV}$ ions, the energy delivered by the former per unit distance (stopping power) is several orders of magnitude smaller than for $\mathrm{MeV}$ ions of the same type. Combined with the fact that $\mathrm{GeV}$ cosmic rays are of much lower abundance than those of smaller energy, the conclusion is that the radiation chemistry caused by $\mathrm{MeV} p^{+}$dominates that of $\mathrm{GeV} p^{+}$in interstellar ices.

\section{EXPERIMENTAL}

Most of the details of our experimental procedures are already in print, and so we present only a summary here. See Loeffler \& Hudson (2012), Ferrante et al. (2008), Hudson \& Moore (2003), and Gerakines et al. (2000) for additional information.

All chemical reagents used for experiments were commercially available and purchased from Sigma-Aldrich, Matheson, and Cambridge Isotopes. These reagents included $\mathrm{O}_{2}, \mathrm{CO}_{2}, \mathrm{CO}$, $\mathrm{CH}_{4}, \mathrm{C}_{2} \mathrm{H}_{2}$, and $\mathrm{C}_{2} \mathrm{H}_{4}$, and selected ${ }^{13} \mathrm{C}$ and ${ }^{18} \mathrm{O}$ isotopologues. Slush baths were employed to remove acetone from commercial acetylene. The water used to make $\mathrm{H}_{2} \mathrm{O}$-rich ices was triply distilled and had a resistivity greater than $10^{7} \Omega \mathrm{cm}$. Ice samples were prepared by vapor-phase condensation for about $1 \mathrm{hr}$ onto pre-cooled (10-20 K) metal substrates (aluminum and gold) in a vacuum chamber $\left(\sim 1 \times 10^{-7}\right.$ Torr $)$. The resulting ice thicknesses were $2.0-3.0 \mu \mathrm{m}$, and these thicknesses were measured with a laser interference system.

Table 1 gives the ice mixtures studied in this work. These are not strictly analogous to the compositions of some interstellar ices, which are known to be dominated by $\mathrm{H}_{2} \mathrm{O}$ or $\mathrm{CO}_{2}$, but rather were selected to probe reactions between specific molecules, and to test for the possibility of solid-phase ketene formation. To a first approximation, the yields we observed, and which we report relative to the hydrocarbon component present, will be proportional to the initial amount of hydrocarbon present in each ice. The precise scaling law we leave for future studies.

Ices were irradiated with $0.8 \mathrm{MeV}$ protons from a Van de Graaff accelerator to doses of 1-25 eV per 16 amu molecule. For the use of proton radiolysis to mimic cosmic-ray bombardment see Moore et al. (2001). Since sample thicknesses were on the order of a few micrometers, the incident protons, having a range of $22 \mu \mathrm{m}$ (Ziegler et al. 1985), penetrated the ices and came to rest in the underlying metal substrate, not in the ices themselves. Far-UV photolyses were performed with a microwave-discharge 
Table 1

Two-Component Ice Mixtures Studied

\begin{tabular}{lc}
\hline \hline Mixture & Approximation Composition \\
\hline $\mathrm{CO}_{2}+{ }^{13} \mathrm{C}_{2} \mathrm{H}_{2}$ & $1: 1$ \\
$\mathrm{O}_{2}+\mathrm{C}_{2} \mathrm{H}_{2}$ & $1: 1$ \\
$\mathrm{O}_{2}+{ }^{13} \mathrm{C}_{2} \mathrm{H}_{2}$ & $1: 1$ \\
${ }^{18} \mathrm{O}_{2}+\mathrm{C}_{2} \mathrm{H}_{2}$ & $1: 1$ \\
$\mathrm{H}_{2} \mathrm{O}+{ }^{13} \mathrm{C}_{2} \mathrm{H}_{2}$ & $5: 1$ \\
$\mathrm{O}_{2}+\mathrm{C}_{2} \mathrm{H}_{4}$ & $1: 10$ \\
${ }^{18} \mathrm{O}_{2}+\mathrm{C}_{2} \mathrm{H}_{4}$ & $1: 10$ \\
$\mathrm{C}^{18} \mathrm{O}_{2}+\mathrm{C}_{2} \mathrm{H}_{4}$ & $1: 1$ \\
$\mathrm{CO}^{2} \mathrm{CO}_{2}$ & $1: 1$ \\
${ }^{13} \mathrm{CO}_{2}+{ }^{13} \mathrm{CH}_{4}$ & $1: 1,10: 1$ \\
$\mathrm{CO}+\mathrm{CH}_{4}$ & $1: 1$ \\
$\mathrm{CO}+{ }^{13} \mathrm{CH}_{4}$ & $1: 1$ \\
\hline
\end{tabular}

hydrogen-flow lamp producing primarily Ly $\alpha$ photons $(10.2 \mathrm{eV}$, $121.6 \mathrm{~nm}, \sim 3 \times 10^{14}$ photons $\left.\mathrm{cm}^{-2} \mathrm{~s}^{-1}\right)$. See Gerakines et al. (2000) for more on the UV technique. The lamp employed was the same as the type used by Ehrenfreund et al. (2001), but with $\sim 30 \%$ of their photon flux at the sample's surface.

Infrared (IR) spectra of $\mathrm{H}_{2} \mathrm{O}$-rich ices usually were recorded as 60 scan accumulations from 4000 to $400 \mathrm{~cm}^{-1}$ before and after exposure to the proton beam or UV lamp, typically at a resolution of $4 \mathrm{~cm}^{-1}$. The inherent widths of IR absorptions in $\mathrm{H}_{2} \mathrm{O}$-dominated ices usually made it unnecessary to employ higher resolutions, but such was not the case with apolar ice samples. Spectra of ices made only of non-polar components (e.g., $\mathrm{O}_{2}+\mathrm{C}_{2} \mathrm{H}_{2}, \mathrm{CO}_{2}+\mathrm{C}_{2} \mathrm{H}_{2}$ ) had sharper lines and were studied at $2 \mathrm{~cm}^{-1}$ resolution with 100 scan accumulations or, in a few cases, at $1 \mathrm{~cm}^{-1}$ resolution. In all cases, the spectrum of an ice was divided by that of the mirror substrate, recorded before the sample's deposition, and the resulting ratio then was converted into absorbance in the usual way $\left(A=-\log \left(I / I_{0}\right)\right)$. Absorbance bands were integrated after subtraction of baselines that best matched the continuum on each side of the IR feature of interest.

We estimated ketene's abundance in our irradiated ices by comparing the IR band areas of ${ }^{13} \mathrm{C}$-labeled ketene $\left(2071 \mathrm{~cm}^{-1}\right)$ and ${ }^{13} \mathrm{CO}_{2}\left(2281 \mathrm{~cm}^{-1}\right)$ in our $\mathrm{CO}_{2}+{ }^{13} \mathrm{C}_{2} \mathrm{H}_{2}$ mixtures. For this estimate, we assumed (1) that the ratio of absolute intensities of $\mathrm{CO}_{2}$ and ketene, as measured in IR transmission experiments, was the same as in our reflectance experiments, (2) that the ${ }^{13} \mathrm{CO}_{2}$-to- ${ }^{12} \mathrm{CO}_{2}$ abundance ratio $\left({ }^{13} \mathrm{C} /{ }^{12} \mathrm{C}\right)$ was $0.011 \mathrm{in} \mathrm{accord}$ with each isotope's natural abundance, and (3) that the band strengths for ${ }^{13} \mathrm{C}$ and ${ }^{12} \mathrm{C}$ isotopologues were essentially the same. The first assumption is likely the main source of error as it has long been known that IR reflectance and transmittance spectra of thin samples $(\sim 1 \mu \mathrm{m})$ can differ and that Beer's Law can fail (e.g., Maeda \& Schatz 1961; Pacansky \& England 1986). To estimate the error involved in assumption (1) we grew a $\mathrm{CO}+$ $\mathrm{CO}_{2}$ (1:1) ice and measured the ${ }^{13} \mathrm{CO}$-to- ${ }^{13} \mathrm{CO}_{2}$ ratio, finding it to differ by as much as a factor of three from expectations (Yamada \& Person 1964; Jiang et al. 1975). This led us to estimate our ketene yield (vide infra) as accurate to a factor of three, an uncertainty we hope to reduce considerably in the future. Finally, we note that for our other ices that are similar in thickness to our $\mathrm{CO}_{2}$-rich samples, we also can estimate ketene's abundance since the absolute intensities of ketene in the two cases will be similar.

To aid in assignments of spectral features, the Spartan software package of Wavefunction, Inc. was used for densityfunctional theory (DFT) calculations at the B3LYP/6-31+G* level to determine isotopic shifts of the most-intense vibrational bands of selected ketene and CO isotoplogues. In many cases, relevant spectral data are in the literature, but our DFT calculations gave a single consistent approach to estimating shifts due to ${ }^{13} \mathrm{C}$ and ${ }^{18} \mathrm{O}$ labels.

\section{RESULTS}

Our initial interest in ketene, aside from astronomical considerations, was motivated by an experiment showing that protonirradiated $\mathrm{H}_{2} \mathrm{O}+\mathrm{C}_{2} \mathrm{H}_{2}$ ices produced $\mathrm{CO}$ (Moore \& Hudson 1998). That a set of reactions would occur in an ice to give $\mathrm{H}-\mathrm{C} \equiv \mathrm{C}-\mathrm{H} \rightarrow \mathrm{C} \equiv \mathrm{O}$, converting a carbon-carbon triple bond into a carbon-oxygen triple bond, was contrary to both experience and expectations, as were similar observations in a later ice-photochemistry experiment of Wu et al. (2002). However, the $\mathrm{C}_{2} \mathrm{H}_{2}$ to $\mathrm{CO}$ conversion could be understood if ketene formed in an intermediate step and then dissociated to give $\mathrm{CO}$. The correct reaction sequence thus was assumed to be $\mathrm{H}-\mathrm{C} \equiv \mathrm{C}-\mathrm{H} \rightarrow$ $\mathrm{H}_{2} \mathrm{C}=\mathrm{C}=\mathrm{O} \rightarrow \mathrm{C} \equiv \mathrm{O}$. Unfortunately, ketene's strongest IR feature, a $\mathrm{C}=\mathrm{C}=\mathrm{O}$ asymmetric stretch, is almost coincident with the intense fundamental vibration of solid CO near $2136 \mathrm{~cm}^{-1}$, making it difficult to observe each molecule in a single ice with infrared spectroscopy. For this reason, much of the new work we report here relies heavily on the use of isotopically labeled compounds to separate the most-intense $\mathrm{CO}$ and ketene features. The great majority of our experiments involved the use of ${ }^{13} \mathrm{C}$ - or ${ }^{18} \mathrm{O}$-enriched reagents, although a small number of deuterated compounds also were studied. The latter proved to give IR spectra with ketene features that overlapped with bands of other products, and so no experiments using deuteriumenriched reagents are reported here.

Table 2 summarizes some literature results for ketene's IR spectrum. Absolute intensities have been measured for only a few features (Berg \& Ewing 1991), with the $v_{2}$ band being by far the strongest, and comparable to the intense OCO asymmetric vibration of $\mathrm{CO}_{2}$. Calculations for all of ketene's mid-IR features show that the $v_{2}$ absorption is 5-10 times stronger than any other (Allen \& Schaefer 1986). In our own work, this IR feature was found to be a sensitive probe of reaction chemistry in ices.

\subsection{Ketene Formation in Apolar Ices}

Previous experiments (Haller \& Pimentel 1962) showed that the far-UV photolysis of $\mathrm{N}_{2} \mathrm{O}$ at $20 \mathrm{~K}$ produces oxygen atoms that react with $\mathrm{C}_{2} \mathrm{H}_{2}$ to make ketene. We have extended and modified this experiment using apolar ices, and Figure 2 shows the results from three different samples. Spectrum (a) is after photolysis of $\mathrm{O}_{2}+\mathrm{C}_{2} \mathrm{H}_{2}$ with each element in its natural abundance. The lone IR peak near $2136 \mathrm{~cm}^{-1}$ is at the position of both $\mathrm{CO}$ and ketene. Trace (b) is the spectrum produced by photolysis of an ice composed of ${ }^{18} \mathrm{O}_{2}+\mathrm{C}_{2} \mathrm{H}_{2}$ and shows two well-resolved features. The one on the left is from labeled ketene $\left(\mathrm{H}_{2} \mathrm{CC}^{18} \mathrm{O}\right)$, while the one on the right is from $\mathrm{C}^{18} \mathrm{O}$. Spectrum (c) is from a photolyzed $\mathrm{O}_{2}+{ }^{13} \mathrm{C}_{2} \mathrm{H}_{2}$ ice, with the assignments being ${ }^{13} \mathrm{CO}$ for the leftmost peak and $\mathrm{H}_{2}{ }^{13} \mathrm{C}^{13} \mathrm{CO}$ for the rightmost.

Taken together, these experiments demonstrate that oxygen atoms, produced by far-UV decomposition of $\mathrm{O}_{2}$, react with acetylene to make ketene. To support our spectral assignments, Table 3 gives the positions we measured for the strongest IR features of $\mathrm{CO}$ and ketene, along with isotopic shifts calculated by density functional theory at the B3LYP/6-31+G* level. Some of the ketene isotopologues we studied have been examined in 


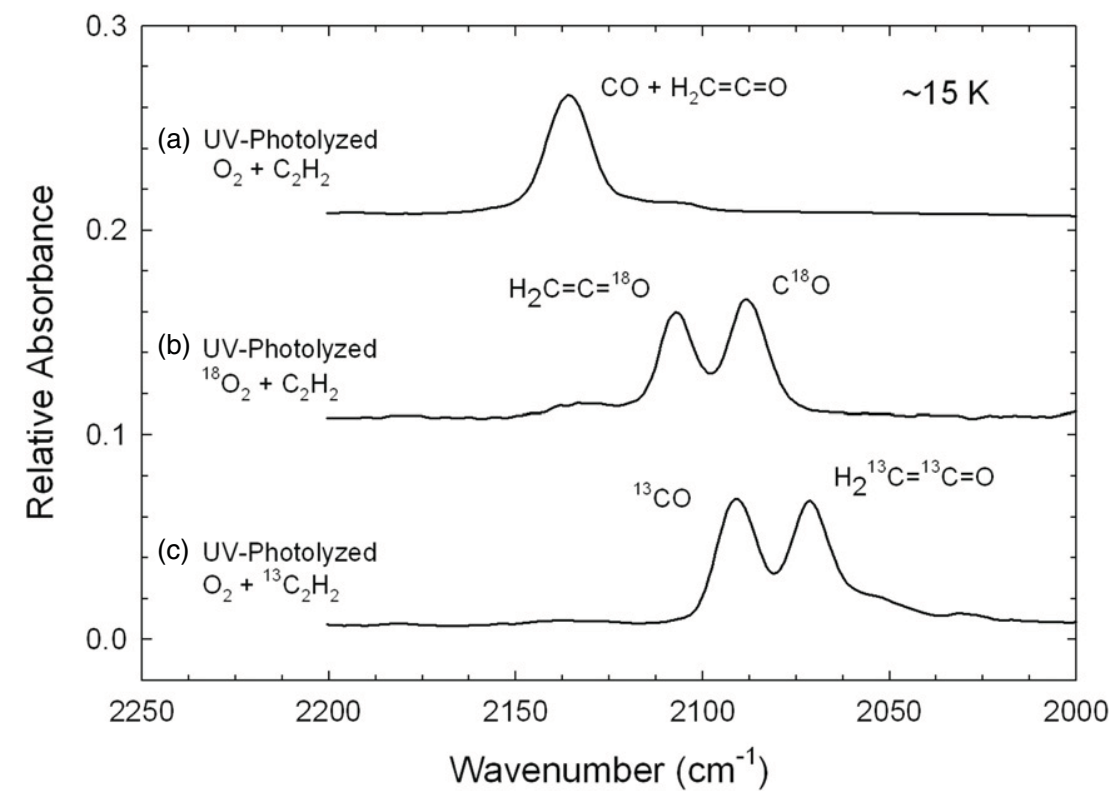

Figure 2. Spectra of the UV photolysis ( 90 minutes) at $\sim 15 \mathrm{~K}_{\text {of }} \mathrm{O}_{2}+\mathrm{C}_{2} \mathrm{H}_{2}$ ices, showing formation of ketene $\left(\mathrm{H}_{2} \mathrm{CCO}\right)$ and $\mathrm{CO}$. The ices initially were composed of (a) $\mathrm{O}_{2}+\mathrm{C}_{2} \mathrm{H}_{2}$, (b) ${ }^{18} \mathrm{O}_{2}+\mathrm{C}_{2} \mathrm{H}_{2}$, and (c) $\mathrm{O}_{2}+{ }^{13} \mathrm{C}_{2} \mathrm{H}_{2}$. No IR features were present in this region before photolysis of the samples. In each case, the initial ice composition was $\mathrm{O}_{2}: \mathrm{C}_{2} \mathrm{H}_{2} \approx 1: 1$.

Table 2

Fundamental Vibrations of Solid-phase Ketene

\begin{tabular}{lccc}
\hline \hline Vibrational Mode & $\begin{array}{c}\text { Position }^{\mathrm{a}} \\
\left(\mathrm{cm}^{-1}\right)\end{array}$ & $\begin{array}{c}\text { Intensity }^{\mathrm{b}} \\
\left(\mathrm{cm} \mathrm{molecule}^{-1}\right)\end{array}$ & Approximate Description $^{\mathrm{c}}$ \\
\hline$\nu_{1}$ & 3043 & $\ldots$ & $\mathrm{C}-\mathrm{H}$ stretch \\
$\nu_{2}$ & 2133 & $1.2 \times 10^{-16}$ & $\mathrm{C}=\mathrm{O}$ stretch \\
$\nu_{3}$ & 1374 & $4.7 \times 10^{-18}$ & $\mathrm{H}-\mathrm{C}-\mathrm{H}$ bend \\
$\nu_{4}$ & 1131 & $\ldots$ & $\mathrm{C}=\mathrm{C}$ stretch \\
$\nu_{5}$ & 3140 & $\ldots$ & $\mathrm{C}-\mathrm{H}$ stretch \\
$\nu_{6}$ & 971 & $\ldots$ & $\mathrm{CH}$ rock \\
$\nu_{7}$ & 440,435 & $\ldots$ & $\mathrm{C}=\mathrm{C}=\mathrm{O}$ bend \\
$\nu_{8}$ & 616 & $\ldots$ & $\mathrm{CH} \mathrm{H}_{2}$ wag \\
$\nu_{9}$ & 529,512 & & $\mathrm{C}=\mathrm{C}=\mathrm{O}$ bend \\
\hline
\end{tabular}

Notes.

${ }^{a}$ Moore \& Pimentel (1963).

${ }^{\mathrm{b}}$ Berg \& Ewing (1991).

${ }^{c}$ Allen \& Schaefer (1986)

Table 3

Positions of Ketene and Carbon Monoxide Isotopologues ${ }^{\mathrm{a}}$

\begin{tabular}{lccc}
\hline \hline Molecule & $\begin{array}{c}\text { Observed Position } \\
\left(\mathrm{cm}^{-1}\right)\end{array}$ & $\begin{array}{c}\text { Observed Isotopic Shift } \\
\left(\mathrm{cm}^{-1}\right)\end{array}$ & $\begin{array}{c}\text { Calculated Isotopic Shift }^{\mathrm{b}} \\
\left(\mathrm{cm}^{-1}\right)\end{array}$ \\
\hline $\mathrm{H}_{2}{ }^{12} \mathrm{C}={ }^{12} \mathrm{C}={ }^{16} \mathrm{O}$ & 2136 & $\ldots$ & $\ldots$ \\
$\mathrm{H}_{2}{ }^{12} \mathrm{C}={ }^{12} \mathrm{C}={ }^{18} \mathrm{O}$ & 2107 & 29 & 28 \\
$\mathrm{H}_{2}{ }^{13} \mathrm{C}={ }^{13} \mathrm{C}={ }^{16} \mathrm{O}$ & 2071 & 65 & 65 \\
$\mathrm{D}_{2}{ }^{12} \mathrm{C}={ }^{12} \mathrm{C}={ }^{16} \mathrm{O}$ & 2109 & 27 & 26 \\
${ }^{12} \mathrm{C}^{16} \mathrm{O}$ & 2136 & $\ldots$ & $\ldots$ \\
${ }^{12} \mathrm{C}^{18} \mathrm{O}$ & 2088 & 48 & 53 \\
${ }^{13} \mathrm{C}^{16} \mathrm{O}$ & 2091 & 45 & 49 \\
\hline
\end{tabular}

Notes.

a Positions observed in our work for each molecule's strongest IR feature.

${ }^{\mathrm{b}}$ Shifts are with reference to the positions of the ${ }^{12} \mathrm{C},{ }^{1} \mathrm{H}$, and ${ }^{16} \mathrm{O}$ isotopologues of ketene and $\mathrm{CO}$.

${ }^{\mathrm{c}}$ Our own density functional calculations.

the gas or liquid phases in other laboratories (e.g., Hochstrasser \& Wirz 1990), and in all cases our measured isotopic shifts are in excellent agreement with published laboratory results and our own calculated values. The results of Figure 2 served to deter- mine spectral positions and acted as preliminary work for our studies of ion-irradiated ices.

Figure 3 shows IR spectra from the experiment represented by Figure 2(b), namely an ${ }^{18} \mathrm{O}_{2}+\mathrm{C}_{2} \mathrm{H}_{2}$ (1:1) ice at $15 \mathrm{~K}$ after several 


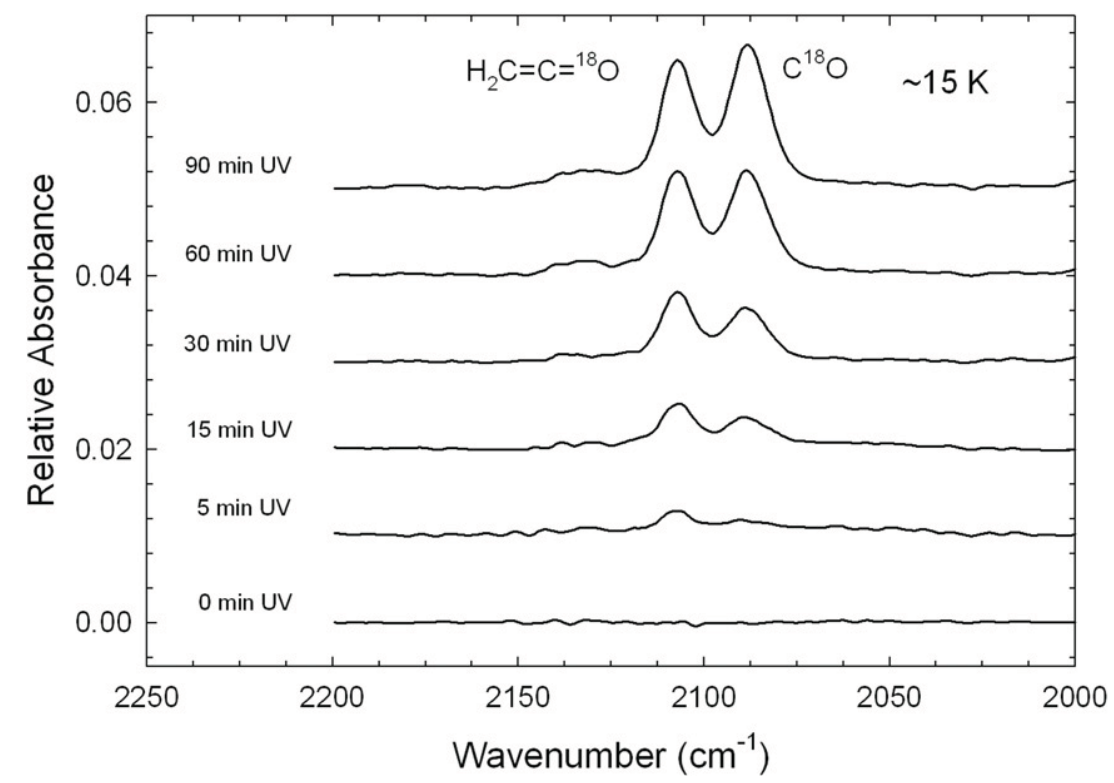

Figure 3. Spectra showing ${ }^{18} \mathrm{O}_{2}+\mathrm{C}_{2} \mathrm{H}_{2}$ (1:1) at $\sim 15 \mathrm{~K}$ after various stages of $\mathrm{UV}$ photolysis (bottom to top).

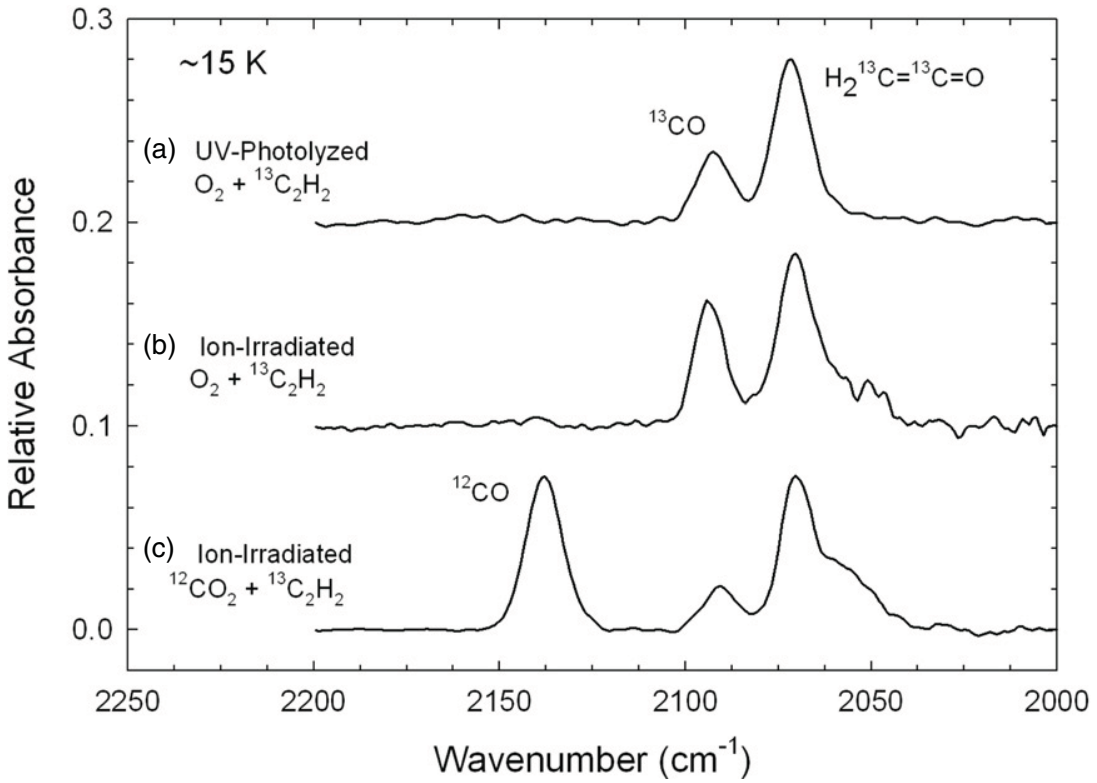

Figure 4. Spectra showing the similarity of reaction products from UV photolysis and proton irradiation, and from $\mathrm{O}_{2}$ and $\mathrm{CO}_{2}$ as sources of oxygen: (a) $\mathrm{O}_{2}+{ }^{13} \mathrm{C}_{2} \mathrm{H}_{2}$ after 5 minute UV photolysis, (b) $\mathrm{O}_{2}+{ }^{13} \mathrm{C}_{2} \mathrm{H}_{2}$ after $2 \times 10^{13} p^{+} \mathrm{cm}^{-2}$, and (c) $\mathrm{CO}_{2}+{ }^{13} \mathrm{C}_{2} \mathrm{H}_{2}$ after $1 \times 10^{14} p^{+} \mathrm{cm}^{-2}$, with each ice initially being a $1: 1$ mixture.

far-UV exposures. The first band to appear was that of ${ }^{18} \mathrm{O}-$ labeled ketene, on the left, followed by the fundamental band of $\mathrm{C}^{18} \mathrm{O}$. This observation is consistent with our hypothesis that the CO we found earlier (Moore \& Hudson 1998) in irradiated acetylene-containing ices was from the sequence $\mathrm{C}_{2} \mathrm{H}_{2} \rightarrow$ $\mathrm{H}_{2} \mathrm{CCO} \rightarrow \mathrm{CO}$. Not shown in the figure, but consistent with this sequence, is the observation that the ketene feature went through a rise and then a fall in intensity with continued photolysis, while the $\mathrm{CO}$ feature continued to grow (vide infra).

Figure 4 shows an important link between the preliminary photolysis work just described and our radiation studies. Traces (a) and (b) of Figure 4 demonstrate that the same IR features are found in UV-photolyzed and ion-irradiated ices, while trace (c) shows that irradiated $\mathrm{CO}_{2}$, like $\mathrm{O}_{2}$, produces oxygen atoms that react with acetylene to make ketene. These spectra unambiguously show that ketene formation occurs in both irradiated and photolyzed apolar ices.

\subsection{Ketene Formation in $\mathrm{H}_{2} \mathrm{O}$-rich Ices}

As preliminary work for our radiation experiments on $\mathrm{H}_{2} \mathrm{O}$ rich ices, we UV-photolyzed a sample made from $\mathrm{H}_{2} \mathrm{O}+{ }^{13} \mathrm{C}_{2} \mathrm{H}_{2}$ $(\sim 5: 1)$. The spectra that resulted are shown in Figure 5. Just as in Figure 3, ketene seems to form first, followed by CO. Figure 6 shows IR spectra from a proton irradiation of $\mathrm{H}_{2} \mathrm{O}+{ }^{13} \mathrm{C}_{2} \mathrm{H}_{2}$ (5:1) at $18 \mathrm{~K}$. The band growing in at $2090 \mathrm{~cm}^{-1}$ is due to ${ }^{13} \mathrm{CO}$, while the adjacent feature is from $\mathrm{H}_{2}{ }^{13} \mathrm{C}^{13} \mathrm{CO}$. That ketene again appeared first, followed by $\mathrm{CO}$, seems clear. Also, this same figure shows that ketene's IR feature rose and fell with dose, while the $\mathrm{CO}$ band continued to grow, supporting the assumed $\mathrm{C}_{2} \mathrm{H}_{2} \rightarrow \mathrm{H}_{2} \mathrm{CCO} \rightarrow \mathrm{CO}$ sequence. Slowly warming this same irradiated ice (Figure 6) from $18 \mathrm{~K}$ to $165 \mathrm{~K}$ caused the ketene absorbance to decrease by about $75 \%$, and essentially removed all of the ${ }^{13} \mathrm{CO}$ absorption. Extending these observations, the reactions in irradiated $\mathrm{H}_{2} \mathrm{O}+{ }^{12} \mathrm{C}_{2} \mathrm{H}_{2}$ ices studied earlier in our 


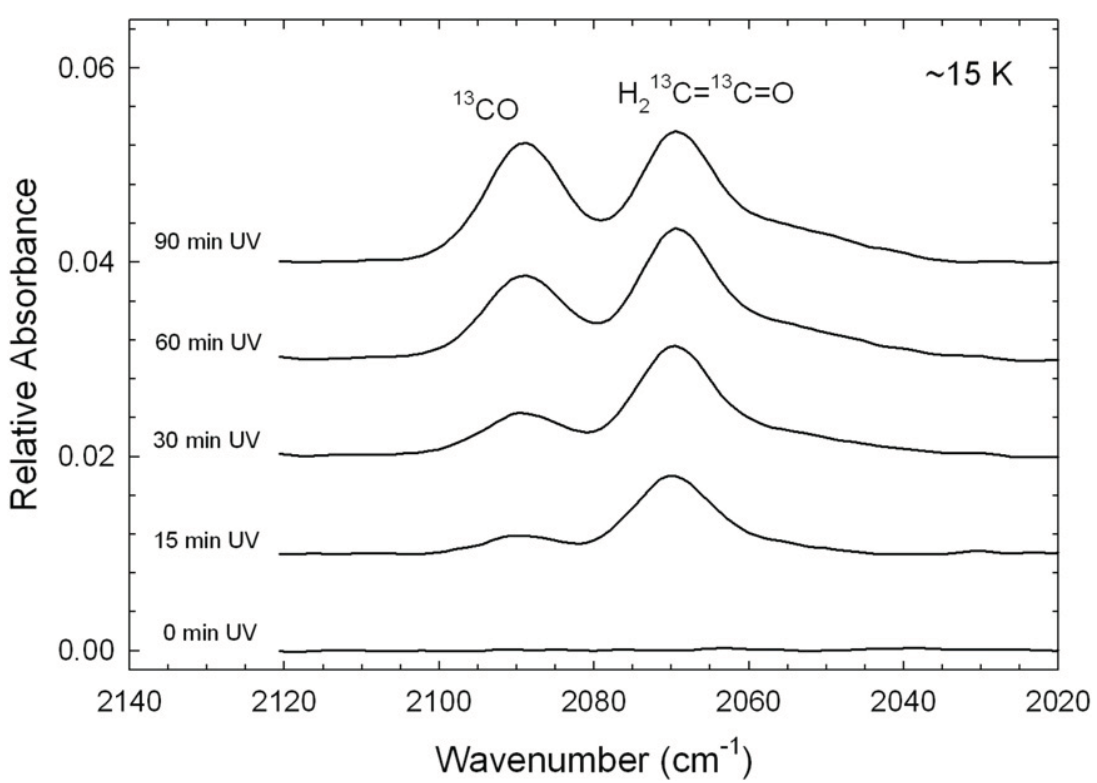

Figure 5. Spectra of $\mathrm{H}_{2} \mathrm{O}+{ }^{13} \mathrm{C}_{2} \mathrm{H}_{2}(5: 1)$ at $\sim 15 \mathrm{~K}$ after various stages of $\mathrm{UV}$ photolysis (bottom to top). The formation of ${ }^{13} \mathrm{C}$-labeled $\mathrm{CO}$ (left) and ketene (right) are shown.

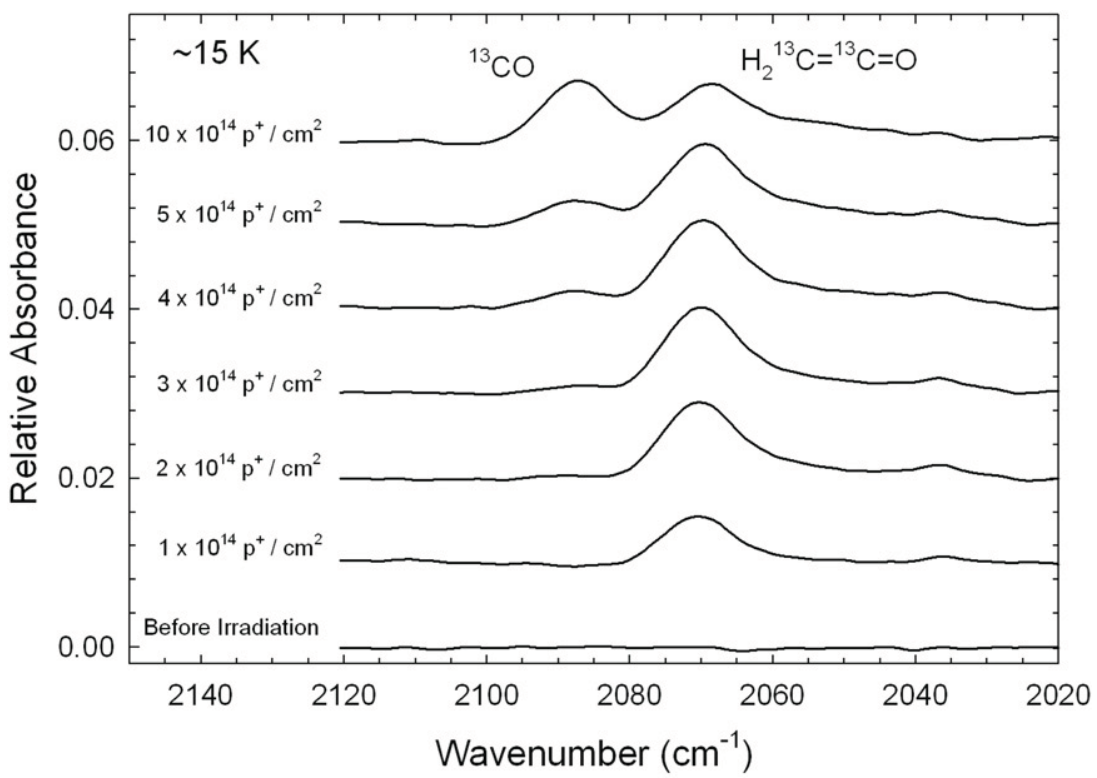

Figure 6. Spectra of $\mathrm{H}_{2} \mathrm{O}+{ }^{13} \mathrm{C}_{2} \mathrm{H}_{2}$ (5:1) after various stages of proton irradiation (bottom to top). The formation of ${ }^{13} \mathrm{C}$-labeled ketene (right) and $\mathrm{CO}$ (left) are shown.

laboratory (Moore \& Hudson 1998) and elsewhere (Wu et al. 2002) also must produce ketene. The CO yields (abundances) we reported earlier in irradiated $\mathrm{H}_{2} \mathrm{O}+{ }^{12} \mathrm{C}_{2} \mathrm{H}_{2}$ ices can only be considered as upper bounds.

\subsection{Other Results}

During the course of our work a few other observations were made that we wish to report. First, Bennett et al. (2005b) have published an extensive study of electron-irradiated $\mathrm{CO}_{2}+\mathrm{C}_{2} \mathrm{H}_{4}$ ice at $10 \mathrm{~K}$, but did not report ketene formation. Their nonobservation of ketene is probably due to their use of reagents having $\mathrm{C}, \mathrm{H}$, and $\mathrm{O}$ in their natural abundances. Figure 7 shows our own IR spectra from radiation experiments with ${ }^{18} \mathrm{O}$-enriched reagents, which confirm ketene formation in ices containing $\mathrm{C}_{2} \mathrm{H}_{4}$ (ethylene). These experiments emphasize the value of isotopically labeled materials in similar studies of ketene in astronomical ice analogs.

Related to this point, in both photolyzed and irradiated $\mathrm{O}_{2}+$ $\mathrm{C}_{2} \mathrm{H}_{2}$ ices we observed not only $\mathrm{CO}$ and ketene synthesis, but also the production of $\mathrm{CO}_{2}$. Isotopically labeled reagents were important in discriminating reaction chemistry from possible contamination by atmospheric $\mathrm{CO}_{2}$.

Another irradiated-ice mixture briefly examined was solidphase $\mathrm{CO}+\mathrm{CH}_{4}$. The experiments of Bennett et al. (2005a) did not include a detection of ketene, which we again suspect was due to the use of reagents with $\mathrm{C}, \mathrm{H}$, and $\mathrm{O}$ in natural abundance. In contrast, when we irradiated ${ }^{13} \mathrm{CO}+{ }^{13} \mathrm{CH}_{4}$ ices, ${ }^{13} \mathrm{C}$-labeled ketene was indeed observed. Besides ketene, we also found the ketenyl radical (HCCO) in several different experiments. Table 4 summarizes the isotopic shifts we observed for $\mathrm{CO}_{2}$ and $\mathrm{HCCO}$ in our work. 


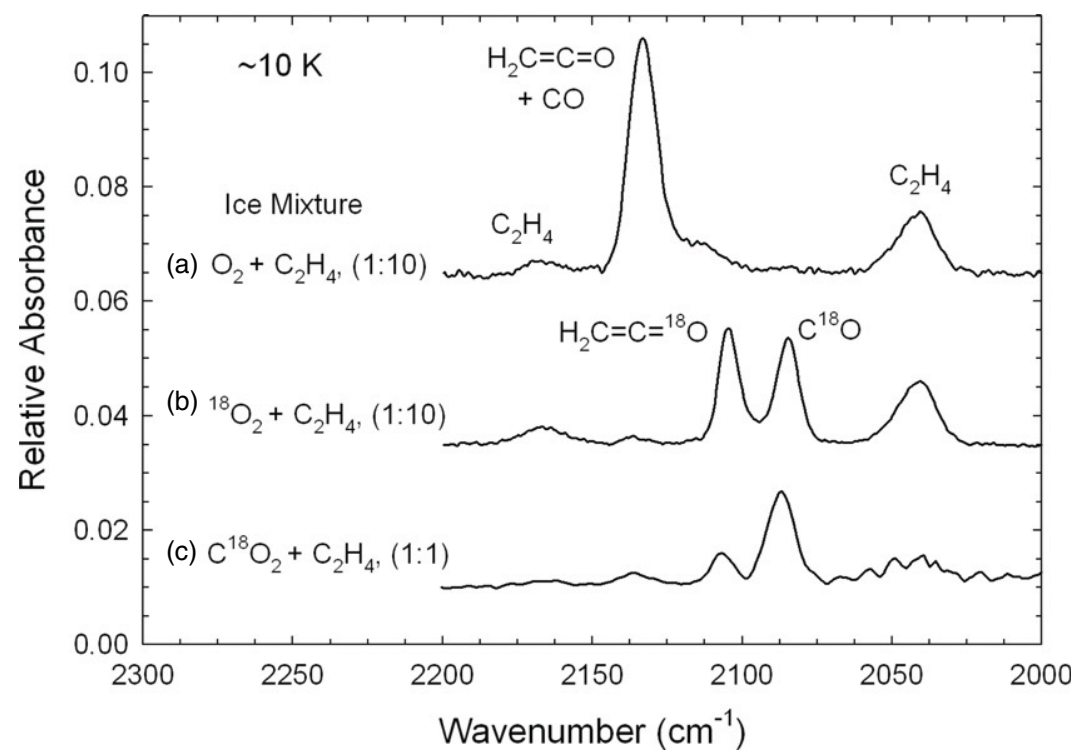

Figure 7. Spectra showing the formation of ketene in irradiated ethylene-containing ices. The formation of ${ }^{18} \mathrm{O}$-labeled ketene (left) and CO (right) are shown. Ion fluences are approximately (a) $1 \times 10^{14} p^{+} \mathrm{cm}^{-2}$, (b) $1 \times 10^{14} \mathrm{p}^{+} \mathrm{cm}^{-2}$, and (c) $2 \times 10^{14} \mathrm{p}^{+} \mathrm{cm}^{-2}$.

Table 4

Positions of Carbon Dioxide and Ketenyl Isotopologues ${ }^{\mathrm{a}}$

\begin{tabular}{lccc}
\hline \hline Initial Ice & $\begin{array}{c}\text { Observed Position and Assignment } \\
\left(\mathrm{cm}^{-1}\right)\end{array}$ & $\begin{array}{c}\text { Observed Isotopic Shift } \\
\left(\mathrm{cm}^{-1}\right)\end{array}$ & $\begin{array}{c}\text { Literature Isotopic Shift } \\
\left(\mathrm{cm}^{-1}\right)\end{array}$ \\
\hline $\mathrm{O}_{2}+\mathrm{C}_{2} \mathrm{H}_{2}$ & $\ldots$ & $\ldots$ \\
$\mathrm{O}_{2}+\mathrm{C}_{2} \mathrm{D}_{2}$ & $2341, \mathrm{CO}_{2}$ & $\ldots$ & $\ldots$ \\
${ }^{18} \mathrm{O}_{2}+\mathrm{C}_{2} \mathrm{H}_{2}$ & $2341, \mathrm{CO}_{2}$ & 34 & $35^{\mathrm{c}}$ \\
$\mathrm{O}_{2}+{ }^{13} \mathrm{C}_{2} \mathrm{H}_{2}$ & $2307, \mathrm{C}^{18} \mathrm{O}_{2}$ & 66 & $66^{\mathrm{c}}$ \\
$\mathrm{CO}+\mathrm{CH}_{4}$ & $2275,{ }^{13} \mathrm{CO}_{2}$ & $\ldots$ & $\ldots$. \\
$\mathrm{CO}+\mathrm{CD}_{4}$ & $2026, \mathrm{HCCO}$ & 29 & $29^{\mathrm{d}}$ \\
$\mathrm{CO}+{ }^{13} \mathrm{CO}+{ }^{13} \mathrm{CH}_{4}$ & $1997, \mathrm{DCCO}$ & 6 & $\ldots$. \\
& $2020, \mathrm{H}^{13} \mathrm{CCO}$ & 58 & $58^{\mathrm{d}}$ \\
\hline
\end{tabular}

Notes.

a Positions observed in our work for each molecule's strongest IR feature.

${ }^{\mathrm{b}}$ Shifts are with reference to the positions of the ${ }^{12} \mathrm{C},{ }^{1} \mathrm{H}$, and ${ }^{16} \mathrm{O}$ isotopologues.

${ }^{c}$ Vasserot et al. (2003) in neon matrices.

${ }^{\mathrm{d}}$ Forney et al. (1995) in neon matrices. No data for $\mathrm{H}^{13} \mathrm{CCO}$ reported, but our own density-functional calculations gave isotopic shifts of 28,5 , and $62 \mathrm{~cm}^{-1}$ for $\mathrm{DCCO}, \mathrm{H}^{13} \mathrm{CCO}$, and $\mathrm{H}^{13} \mathrm{C}^{13} \mathrm{CO}$, respectively.

Finally, to help elucidate the reaction paths leading to ketene we performed two types of scavenging experiments. Adding $\sim 1 \% \mathrm{NH}_{3}$, an $\mathrm{H}^{+}$scavenger, to $\mathrm{H}_{2} \mathrm{O}+\mathrm{C}_{2} \mathrm{H}_{2}$ ices before irradiation scarcely changed the experimental results. Similarly, adding $\sim 1 \% \quad \mathrm{~N}_{2} \mathrm{O}$, an electron scavenger, to $\mathrm{H}_{2} \mathrm{O}+\mathrm{C}_{2} \mathrm{H}_{2}$ did not alter the final products. These experiments suggested that the observed products arose primarily through free-radical pathways, as opposed to acid-base chemistry $\left(\mathrm{H}^{+}\right.$transfers $)$or redox processes ( $e^{-}$transfers). See Hudson \& Moore (2000, and references therein) for another application of chemical scavengers to interstellar ice analogs.

\section{DISCUSSION}

\subsection{Ketene Spectra and Chemistry}

In general, the positions of IR absorptions in a mixed molecular solid are seldom the same as the positions of the individual components in their pure states (e.g., Knez et al. 2012; Palumbo et al. 1995). This led us to rely heavily on ketene's isotopic shifts, as given in Table 3, in interpreting our results, with the good agreement between observed and
Table 5

O-atom Capture by Acetylene and Related Triply bonded Molecules

\begin{tabular}{ll}
\hline \hline Reaction & \multicolumn{1}{c}{ Reference } \\
\hline $\mathrm{H}-\mathrm{C} \equiv \mathrm{C}-\mathrm{H}+\mathrm{O} \rightarrow \mathrm{H}_{2} \mathrm{C}=\mathrm{C}=\mathrm{O}$ & Haller \& Pimentel (1962) \\
$\mathrm{H}-\mathrm{C} \equiv \mathrm{N}:+\mathrm{O} \rightarrow \mathrm{HN}=\mathrm{C}=\mathrm{O}$ & Crowley \& Sodeau (1989) \\
$: \mathrm{C} \equiv \mathrm{O}:+\mathrm{O} \rightarrow \mathrm{O}=\mathrm{C}=\mathrm{O}$ & Elsila et al. (1997) \\
$: \mathrm{N} \equiv \mathrm{N}:+\mathrm{O} \rightarrow \mathrm{N}=\mathrm{N}=\mathrm{O}$ & Elsila et al. (1997) \\
\hline
\end{tabular}

calculated shifts supporting our ketene spectral assignments. A second line of support came from comparisons to the similar chemical systems in Table 5. The table gives products of triply bonded molecules after reaction with photochemically produced oxygen atoms, and in each case the resulting product is from an $\mathrm{O}$-atom capture. Therefore, we took reactions (1) and (2) below as the source of ketene from $\mathrm{O}_{2}$ dissociation:

$$
\begin{gathered}
\mathrm{O}_{2} \rightarrow \mathrm{O}+\mathrm{O} \\
\mathrm{O}+\mathrm{C}_{2} \mathrm{H}_{2} \rightarrow \mathrm{H}_{2} \mathrm{C}=\mathrm{C}=\mathrm{O} .
\end{gathered}
$$


Analogous reactions between either $\mathrm{NH}$ or $\mathrm{CH}_{2}$ (isoelectronic to $\mathrm{O}$ ) and the four triply bonded molecules of Table 5 can be written (e.g., Milligan \& Jacox 1963; Moore \& Pimentel 1964).

Our $\mathrm{CO}_{2}+\mathrm{C}_{2} \mathrm{H}_{2}$ ice (Figure 4) also gave ketene, presumably in a process in which reaction (1) was replaced by $\mathrm{CO}_{2} \rightarrow$ $\mathrm{CO}+\mathrm{O}$, followed by reaction (2). We estimate that in these experiments, the maximum yield of ketene is $\sim 0.2 \%$ with respect to the initial abundance of $\mathrm{C}_{2} \mathrm{H}_{2}$. Our $\mathrm{O}_{2}+\mathrm{C}_{2} \mathrm{H}_{2}$ experiments gave a similar yield, $0.5 \%$. These numbers will increase if one considers that ketene is also likely the source for the ${ }^{13} \mathrm{CO}$ formed in these experiments. In the three ices containing ethylene (Figure 7), the oxidation sequence $\mathrm{C}_{2} \mathrm{H}_{4} \rightarrow$ $\mathrm{C}_{2} \mathrm{H}_{2}$ was the source of acetylene for reaction (2).

Turning to our $\mathrm{H}_{2} \mathrm{O}$-rich samples (polar ices), although the ketene seen in ion-irradiated $\mathrm{H}_{2} \mathrm{O}+\mathrm{C}_{2} \mathrm{H}_{2}$ solids also may come from $\mathrm{O}$-atom reactions, we tend to favor a different pathway. Radiolysis dissociates $\mathrm{H}_{2} \mathrm{O}$ into $\mathrm{H}$ atoms, hydroxyl radicals $(\mathrm{OH})$, and a number of other reactive species (e.g., $\mathrm{H}_{3} \mathrm{O}^{+}$, $\left.e^{-}, \mathrm{HO}_{2}\right)$. Acetylene undergoes $\mathrm{H}$ and $\mathrm{OH}$ addition reactions (Hudson \& Moore 1997) to make ethylene $\left(\mathrm{C}_{2} \mathrm{H}_{4}\right)$, ethane $\left(\mathrm{C}_{2} \mathrm{H}_{6}\right)$, and ethanol $\left(\mathrm{C}_{2} \mathrm{H}_{5} \mathrm{OH}\right)$ through

$$
\begin{gathered}
\mathrm{C}_{2} \mathrm{H}_{2} \rightarrow \mathrm{C}_{2} \mathrm{H}_{4} \rightarrow \mathrm{C}_{2} \mathrm{H}_{6} \\
\mathrm{C}_{2} \mathrm{H}_{2} \rightarrow \mathrm{C}_{2} \mathrm{H}_{4} \rightarrow \mathrm{C}_{2} \mathrm{H}_{5} \mathrm{OH},
\end{gathered}
$$

but vinyl alcohol, $\mathrm{C}_{2} \mathrm{H}_{3} \mathrm{OH}$, forms if the initial reaction in reaction (3) or (4) involves $\mathrm{H}$ and $\mathrm{OH}$ radicals. Earlier we identified vinyl alcohol as a product in irradiated $\mathrm{H}_{2} \mathrm{O}+\mathrm{C}_{2} \mathrm{H}_{2}$ ices, and observed that its abundance first rose and then fell with increasing radiation dose (Hudson \& Moore 2003). This fall in vinyl alcohol's abundance has multiple causes, including the molecule's isomerization into acetaldehyde (Erlenmeyer 1881). An additional destructive path is vinyl alcohol's direct decomposition into ketene by $\mathrm{H}_{2}$ elimination, the assumed sequence being as shown in reaction (5).

$$
\mathrm{C}_{2} \mathrm{H}_{3}(\mathrm{OH}) \rightarrow \mathrm{H}_{2} \mathrm{C}=\mathrm{C}=\mathrm{O}+\mathrm{H}_{2} \text {. }
$$

An alternate route to ketene from $\mathrm{H}_{2} \mathrm{O}+\mathrm{C}_{2} \mathrm{H}_{2}$ ices can be envisioned through $\mathrm{HC}(=\mathrm{O}) \mathrm{CH}_{3}$ (acetaldehyde) in the sequence

$$
\begin{aligned}
\mathrm{HC} & \equiv \mathrm{CH} \rightarrow \mathrm{H}_{2} \mathrm{C}=\mathrm{CH}(\mathrm{OH}) \rightarrow \mathrm{HC}(=\mathrm{O}) \mathrm{CH}_{3} \\
& \rightarrow \mathrm{H}_{2} \mathrm{C}=\mathrm{C}=\mathrm{O}+\mathrm{H}_{2}
\end{aligned}
$$

although we have not yet investigated this pathway in detail. Similar reactions will apply to UV-photolyzed $\mathrm{H}_{2} \mathrm{O}+\mathrm{C}_{2} \mathrm{H}_{2}$ ices. See Hawkins \& Andrews (1983) for a discussion of photoelimination of $\mathrm{H}_{2}$ from ketene in inert-gas matrices.

As already stated, reaction (5) competes with vinyl alcohol destruction along other paths. Such competing reactions, and our earlier estimate (Hudson \& Moore 2003) of 40\% for the conversion of acetylene into vinyl alcohol in an $\mathrm{H}_{2} \mathrm{O}$-rich ice, suggest that any yield of ketene must be less than this value. For the radiation experiment of Figure 6, half of the $\mathrm{C}_{2} \mathrm{H}_{2}$ initially present was lost after a fluence of about $4 \times 10^{14} p^{+} \mathrm{cm}^{-2}$, which also corresponded with roughly the maximum amount of ketene observed. Comparing the band area of our ketene produced in $\mathrm{H}_{2} \mathrm{O}$-rich ices to band areas in ices of similar thickness, we estimate a maximum acetylene-to-ketene yield of $\sim 0.5 \%$ for the experiment of Figure 6, which is comparable to the values obtained in our $\mathrm{CO}_{2}+\mathrm{C}_{2} \mathrm{H}_{2}$ and $\mathrm{O}_{2}+\mathrm{C}_{2} \mathrm{H}_{2}$ mixtures. This yield will at least double if we assume that ketene is also the source for all of the ${ }^{13} \mathrm{CO}$ formed in this same experiment (IR band shown in Figure 6). Note that nearly all such calculations of reaction yields in ices are hindered by the lack of precise measurements for such quantities as IR band strengths, densities, and refractive indices (Satorre et al. 2008).

The focus of our work has been ketene's formation in interstellar ices, but we also have observed several ketene decomposition products such as $\mathrm{CO}, \mathrm{CO}_{2}$, and ketenyl (HCCO). Ketene dissociation can account for $\mathrm{CO}$, which in reaction with either $\mathrm{O}$ atoms or $\mathrm{OH}$ radicals will give $\mathrm{CO}_{2}$. Direct photo- or radiolytic dissociation of ketene,

$$
\mathrm{H}_{2} \mathrm{C}=\mathrm{C}=\mathrm{O} \rightarrow \mathrm{HCCO}+\mathrm{H}
$$

or $\mathrm{H}$-atom abstraction

$$
\mathrm{H}+\mathrm{H}_{2} \mathrm{C}=\mathrm{C}=\mathrm{O} \rightarrow \mathrm{H}_{2}+\mathrm{HCCO}
$$

will generate ketenyl radicals. We note in passing that the ketenyl radical $(\mathrm{H}-\mathrm{C}=\mathrm{C}=\mathrm{O})$ and what is called the ethynyloxy radical $(\mathrm{H}-\mathrm{C} \equiv \mathrm{C}-\mathrm{O})$ are related by way of resonance $(\mathrm{H}-\mathrm{C}=\mathrm{C}=\mathrm{O} \leftrightarrow$ $\mathrm{H}-\mathrm{C} \equiv \mathrm{C}-\mathrm{O})$, and so are the same species. We also caution that what modern chemists call ketenyl occasionally has been termed "ketyl" in the astronomical literature (e.g., Turner \& Sears 1989; Ruiterkamp et al. 2007).

\subsection{Ketene and Astrochemistry}

The radiation doses that icy grain mantles in dense interstellar clouds are expected to receive are on the order of $3 \mathrm{eV}$ molecule ${ }^{-1}$ over a million years (Moore et al. 2001). The spectra of our Figure 6 are for an $\mathrm{H}_{2} \mathrm{O}+\mathrm{C}_{2} \mathrm{H}_{2}$ ice with the conversion between fluence and dose being $1 \times 10^{14} p^{+} \mathrm{cm}^{-2} \approx$ $1 \mathrm{eV}$ molecule ${ }^{-1}$. Therefore, the fact that we see ketene formation after $\sim 1 \mathrm{eV}$ molecule ${ }^{-1}$ suggests that ketene should readily form in dark clouds from reactions between $\mathrm{H}_{2} \mathrm{O}$-ice and trapped $\mathrm{C}_{2} \mathrm{H}_{2}$. A similar conclusion follows for $\mathrm{CO}_{2}$-rich ices containing $\mathrm{C}_{2} \mathrm{H}_{2}$, based on Figure 4. For photolysis experiments, the time to convert acetylene to ketene can be estimated from Ehrenfreund et al. (2001), who determined that 32 million years of UV exposure in a dark cloud was comparable to about $1000 \mathrm{~s}$ of photolysis with their lamp. For our own UV experiments, conducted at a lower photon flux, the conversion is about $3000 \mathrm{~s}$ for 32 million years in a dense molecular cloud. Since our ice experiments readily showed ketene formation after $\sim 10$ minutes the equivalent reaction time in a cold, dense interstellar cloud would be around 6 million years.

Taken together, our experiments demonstrate the relative ease of radiation synthesis of ketene in interstellar environments, and in both polar and apolar ices. For polar ices, only $\mathrm{H}_{2} \mathrm{O}, \mathrm{C}_{2} \mathrm{H}_{2}$, and a suitable source of energy, are needed; for apolar ices, $\mathrm{O}$ atoms and $\mathrm{C}_{2} \mathrm{H}_{2}$ suffice. Acetylene, water, oxygen atoms, and cosmic, or UV, radiation are all part of the interstellar environment and so ketene is expected in interstellar ices. Moreover, ketene has long been suspected to form by the decomposition of most any molecule with the $-\mathrm{CH}_{2}-\mathrm{C}(=\mathrm{O})$ - group (Wilsmore 1907), and so the gas-phase presence of many known interstellar molecules necessarily suggests the presence of ketene as well. Among these molecules are acetic acid, acetone, acetaldehyde, and acetamide, all shown in Figure 8. Conversely, reactions that are the reverse of those in Figure 8 might prove to be a low-temperature source of acetic acid and the other interstellar molecules shown.

A possible complication arising from our work on ketene formation is that the overlap of the IR bands of solid CO and solid ketene near $2140 \mathrm{~cm}^{-1}(4.67 \mu \mathrm{m})$ could require modifications 
ketene formation (general pattern)

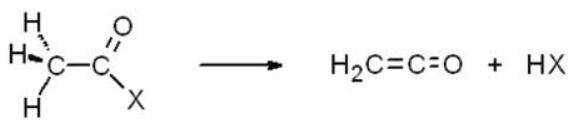

acetic acid

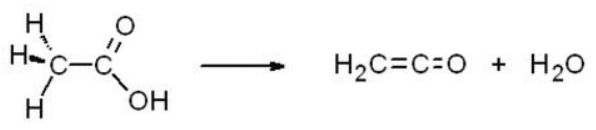

acetone

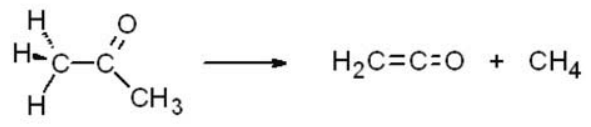

acetaldehyde

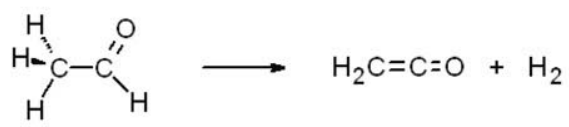

acetamide

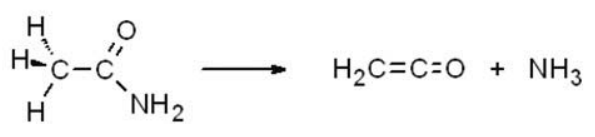

Figure 8. Experiments have shown that the four interstellar molecules named on the left can decompose to give ketene. See the Introduction for references. Solid wedges represent chemical bonds coming out of the plane of the drawing and toward the reader, while dashed wedges represent chemical bonds going behind the plane of the drawing and away from the reader.

to the reported solid-phase $\mathrm{CO}$ abundances in interstellar ices (Gibb et al. 2004). However, we believe that such changes are likely to be small. If the cometary abundance of $\mathrm{C}_{2} \mathrm{H}_{2}$, $\sim 0.3 \%$ of $\mathrm{H}_{2} \mathrm{O}$ (Mumma \& Charnley 2011), is comparable to the abundance of acetylene in an interstellar ice then even complete acetylene-to-ketene conversion $\left(\mathrm{H}-\mathrm{C} \equiv \mathrm{C}-\mathrm{H} \rightarrow \mathrm{H}_{2} \mathrm{C}=\mathrm{C}=\mathrm{O}\right.$ ) would not significantly alter the reported $>\sim 3 \% \mathrm{CO}$ seen in interstellar ices. A possible exception might be interstellar clouds that have warmed sufficiently to remove some solid CO from grains by sublimation, leaving ketene as a more-significant contributor to the IR band near $2140 \mathrm{~cm}^{-1}$ (4.67 $\left.\mu \mathrm{m}\right)$.

While much of our work has focused on interstellar chemistry, applications to solar system astrochemistry are possible. A radiation dose of about $5 \mathrm{eV}$ molecule ${ }^{-1}$ is expected at a $5 \mathrm{~m}$ depth to an Oort-Cloud comet over the age of the solar system, $\sim 4.6 \times 10^{9} \mathrm{yr}$ (Moore et al. 2001). This means that even if ketene were not to form in interstellar ices, its postaccretion synthesis from cometary $\mathrm{H}_{2} \mathrm{O}$-ice and $\mathrm{C}_{2} \mathrm{H}_{2}$ trapped in a comet's nucleus is expected. Warming of a cometary ice will release ketene, primarily at the temperature where the $\mathrm{H}_{2} \mathrm{O}$ ice undergoes sublimation (Hudson \& Donn 1991). The extent to which any such cometary $\mathrm{H}_{2} \mathrm{C}=\mathrm{C}=\mathrm{O}$ would subsequently dissociate in the gas phase, contributing to a $\mathrm{CO}$ distributed source, would depend on the available UV light, a possibility that remains to be explored. This same pathway for ketene formation also may have implications for TNO chemistry since both $\mathrm{CH}_{4}$ and CO have been seen as ices on Pluto (Grundy \& Buie 2001).

A final application of our work concerns meteoritic chemistry. Cooper et al. (2011) have analyzed the organic component of a carbonaceous meteorite (Murchison) and identified pyruvic acid, citric acid, and several other metabolism precursors. The interstellar synthetic paths for these materials remain unknown, but an intriguing possibility is that they all originate with the formation of ketene and its subsequent reaction to make pyruvonitrile, $\mathrm{H}_{3} \mathrm{C}-\mathrm{C}(=\mathrm{O})-\mathrm{CN}$. The decomposition of pyruvonitrile to make ketene has been demonstrated at $\sim 10 \mathrm{~K}$ in argon matri- ces (Guennoun et al. 2005). Now that we have shown that ketene is easily formed in ices from interstellar molecules, new work is needed to characterize the reverse process, ketene $\rightarrow$ pyruvonitrile. In short, the laboratory results reported in the present paper demonstrate ketene formation in ices and thereby lend support to the possible formation of far-more complex organics as outlined elsewhere (Cooper et al. 2011). Details of the low-temperature "ketene $\rightarrow$ pyruvonitrile $\rightarrow$ complex organics" process remain to be studied.

\section{SUMMARY AND CONCLUSIONS}

Our experiments have shown that ketene formation can occur in polar and apolar ices dominated by known interstellar molecules such as $\mathrm{C}_{2} \mathrm{H}_{2}, \mathrm{CH}_{4}, \mathrm{H}_{2} \mathrm{O}, \mathrm{CO}_{2}$, and $\mathrm{O}_{2}$. Both radiolysis and photolysis can initiate ketene syntheses, and with radiolytic yields on the order of $0.1 \%-1 \%$. Although multiple reaction pathways to ketene can be envisioned, our experiments suggest that a free-radical reaction mechanism is operative, implying that ketene formation will not be blocked by solidphase $\mathrm{NH}_{3}$ (a base) in interstellar ices. In polar ices, ketene formation is an intermediate step in the solid-phase oxidation of $\mathrm{C}_{2} \mathrm{H}_{2}$ to $\mathrm{CO}$, the sequence being

$$
\mathrm{C}_{2} \mathrm{H}_{2} \rightarrow \mathrm{CH}_{2} \mathrm{CH}(\mathrm{OH}) \rightarrow \mathrm{H}_{2} \mathrm{C}=\mathrm{C}=\mathrm{O} \rightarrow \mathrm{CO} \text {. }
$$

In apolar $\left(\mathrm{H}_{2} \mathrm{O}\right.$-poor $)$ ices, both $\mathrm{CO}_{2}$ and $\mathrm{O}_{2}$ can serve as the source of $\mathrm{O}$ atoms for ketene formation and both $\mathrm{C}_{2} \mathrm{H}_{2}$ and $\mathrm{C}_{2} \mathrm{H}_{4}$ can serve as the carbon source. The thermal stability of ketene in $\mathrm{H}_{2} \mathrm{O}$-rich ices is such that some of it will be retained until the $\mathrm{H}_{2} \mathrm{O}$-ice sublimes. A similar conclusion applies to ketene in $\mathrm{CO}_{2}$-rich ices.

To extend these experiments, better measurements of reaction yields are needed, which in some cases will mean new work to reduce uncertainties in the relevant IR-band strengths. The reactions of Figures 1 and 8 also need further study in the solid state, as does ketene formation in more-complex ice mixtures. In all cases, IR spectroscopy experiments should use isotopically enriched reagents to distinguish $\mathrm{CO}$ from ketene. Experiments that do not, and predictions from computational models arising from them, should be viewed with caution.

This work was generously supported by the NASA Astrobiology Institute's Goddard Center for Astrobiology and NASA's Exobiology Program. Steve Brown, Tom Ward, and Eugene Gerashchenko, members of the Radiation Effects Facility at the NASA Goddard Space Flight Center, are thanked for operation of the proton accelerator. Perry Gerakines is acknowledged for helpful comments and day-to-day laboratory assistance.

\section{REFERENCES}

Allen, A. D., \& Tidwell, T. T. 2012, Eur. J. Org. Chem., 2012, 1081

Allen, W. D., \& Schaefer, H. F., III 1986, JCP, 81, 2212

Bacmann, A., Taquet, V., Faure, A., Kahane, C., \& Ceccarelli, C. 2012, A\&A, 541, L12

Bennett, C. J., Jamieson, C. S., Osamura, Y., \& Kaiser, R. I. 2005a, ApJ, 624, 1097

Bennett, C. J., Osamura, Y., Lebar, M. D., \& Kaiser, R. I. 2005b, ApJ, 634, 698 Berg, O., \& Ewing, G. E. 1991, JPhCh, 95, 2908

Brown, R. D., Cragg, D. M., Godfrey, P. D., Irvine, W. M., \& McGonagle, D. 1991, OLEB, 21, 399

Charnley, S. B., Tielens, A. G. G. M., \& Millar, T. J. 1992, ApJL, 399, L71

Cooper, G., Reed, C., Nguyen, D., Carter, M., \& Wang, Y. 2011, PNAS, 108, 14015

Crovisier, J., Encrenaz, T., \& Combes, M. 1991, Natur, 353, 610 
Crowley, J. N., \& Sodeau, J. R. 1989, JPhCh, 93, 3100

Ehrenfreund, P., Bernstein, M. P., Dworkin, J. P., Sandford, S. A., \& Allamandola, L. J. 2001, ApJL, 550, L95

Elsila, J., Allamandola, L. J., \& Sandford, S. A. 1997, ApJ, 479, 818

Erlenmeyer, E. 1881, Chem. Ber., 14, 320

Ferrante, R. F., Moore, M. H., Spiliotis, M. M., \& Hudson, R. L. 2008, ApJ, 684,1210

Forney, D., Jacox, M. E., \& Thompson, W. E. 1995, JMoSp, 170, 178

Gerakines, P. A., \& Moore, M. H. 2001, Icar, 154, 372

Gerakines, P. A., Moore, M. H., \& Hudson, R. L. 2000, A\&A, 357, 793

Gibb, E. L., Whittet, D. C. B., Boogert, A. C. A., \& Tielens, A. G. G. M. 2004, ApJS, 151, 35

Grundy, W. M., \& Buie, M. W. 2001, Icar, 153, 248

Guennoun, Z., Couturier-Tamburelli, I., Combes, S., Aycard, J. P., \& Pietri, N. 2005, JPCA, 109, 11733

Hagemeyer, H. J. 1949, Ind. Eng. Chem., 41, 765

Haller, I., \& Pimentel, G. C. 1962, JACS, 84, 2855

Hawkins, M., \& Andrews, L. 1983, JACS, 105, 2523

Herbst, E., \& Leung, C. M. 1986, ApJ, 310, 378

Hochstrasser, R., \& Wirz, J. 1990, Angew. Chem. Int. Ed. Eng1., 29, 411

Hudson, R. L., \& Donn, B. 1991, Icar, 94, 326

Hudson, R. L, \& Moore, M. H. 1997, Icar, 126, 233

Hudson, R. L, \& Moore, M. H. 2000, A\&A, 357, 787

Hudson, R. L., \& Moore, M. H. 2003, ApJL, 586, L107

Hudson, R. L., Moore, M. H., \& Gerakines, P. A. 2001, ApJ, 550, 1140

Irvine, W. M., Friberg, P., Kaifu, N., et al. 1989, ApJ, 342, 871

Jiang, G. J., Person, W. B., \& Brown, K. G. 1975, JCP, 64, 1201

Johansson, L. E. B., Andersson, C., Ellder, J., et al. 1984, A\&A, 130, 227

Knez, C., Moore, M. H., Ferrante, R. F., \& Hudson, R. L. 2012, ApJ, 748,97

Krantz, A. 1973, J. Chem. Soc. Chem. Commun., 18, 670

Loeffler, M. J., \& Hudson, R. L. 2012, Icar, 219, 561

Macoas, E. M. S., Khriachtchev, L, Fausto, R., \& Rasanen, M. 2004, JPCA, 108,3380

Maeda, S., \& Schatz, P. N. 1961, JCP, 35, 1617

Milligan, D. E., \& Jacox, M. E. 1963, JACS, 85, 278

Moore, C. B., \& Pimentel, G. C. 1963, JCP, 38, 2816
Moore, C. B., \& Pimentel, G. C. 1964, JCP, 41, 3504

Moore, M. H., \& Hudson, R. L. 1998, Icar, 135, 518

Moore, M. H., Hudson, R. L., \& Gerakines, P. A. 2001, AcSpe, 57, 843

Muller, S., Beelen, A., Guélin, M., et al. 2011, A\&A, 535, A103

Mumma, M. J., \& Charnley, S. B. 2011, ARA\&A, 49, 471

Orr, R. K., \& Calter, M. A. 2003, Tetrahedron, 59, 3545

Pacansky, J., \& England, C. D. 1986, JPhCh, 90, 4499

Palumbo, M. E., Tielens, A. G. G. M., \& Tokunaga, A. T. 1995, ApJ, 449,674

Paull, D. H., Weatherwax, A., \& Lectka, T. 2009, Tetrahedron, 65, 6771

Pimblott, S. M., \& LaVerne, J. A. 2007, RaPC, 76, 1244

Quadbeck, G. 1956, Angew. Chemie, 68, 361

Romano, R. M., Védova, C., \& Downs, A. J. 2002, JPCA, 106, 7235

Rowland, B., \& Hess, W. P. 1997, JPCA, 102, 8049

Ruiterkamp, R., Charnley, S. B., Butner, H. M., et al. 2007, Ap\&SS, 310, 181

Satorre, M. Á., Domingo, M., Millán, C., et al. 2008, P\&SS, 56, 1748

Schriver, A, Coanga, J. M., Schriver-Mazzuoli, L., \& Ehrenfreund, P. 2004, CP, 303, 13

Spinks, J. W. T., \& Woods, R. J. 1964, An Introduction to Radiation Chemistry (New York: Wiley), 70

Staudinger, H. 1912, Die Ketene (Verlag: Stuttgart)

Tidwell, T. T. 1990, Acc. Chem. Res., 23, 273

Tidwell, T. T. 2005, Angew. Chem. Int. Ed., 44, 5778

Turner, B. E. 1977, ApJL, 213, L75

Turner, B. E., \& Sears, T. J. 1989, ApJ, 340, 900

Turner, B. E., Terzieva, R., \& Herbst, E. 1999, ApJ, 518, 699

Vasserot, A.-M., Gauthier-Roy, B., Chabbi, H., \& Abouaf-Marguin, L. 2003, JMoSp, 220, 201

Wang, S. C., \& Schueler, F. W. 1949, JChEd, 26, 323

Wilsmore, N. T. M. 1907, J. Chem. Soc., 91, 1938

Wilsmore, N. T. M., \& Stewart, A. W. 1907, Natur, 75, 510

Wu, C. Y. R., Judge, D. L., Cheng, B-M., et al. 2002, Icar, 156, 456

Yamada, H., \& Person, W. B. 1964, JCP, 41, 2478

Zhang, X. K., Parnis, J. M., Lewars, E. G., \& March, R. E. 1997, CaJCh, 75, 276

Ziegler, J. F., Biersack, J. P., \& Littmark, U. 1985, The Stopping and Range of Ions in Solids (New York: Pergamon), http://www.srim.org/ 